\title{
Impact of MTNs “I Don Port” Television Campaign on the Porting Decisions of GSM Subscribers
}

\author{
Chioma, Patricia E. (Phd) ${ }^{1}$, Morgan, Olaronke O. ${ }^{1}$, Onuiri, Ernest E ${ }^{2}$ \\ and Ogungbamigbe Olukemi $\mathrm{O}^{3}$ \\ ${ }^{1}$ Department of Mass Communication, Babcock University, Ilishan-Remo, Ogun State, Nigeria \\ ${ }^{2}$ Department of Computer Science, Babcock University, Ilishan-Remo, Ogun State, Nigeria \\ ${ }^{3}$ Department of Mass Communication, Federal Polytechnic, Offa, Kwara State \\ chiomapa@babcock.edu.ng
}

\begin{abstract}
Businesses the world over rely on advertisements to promote their brands or products. This is largely seen as a way of creating awareness as pertains the value proposition of the business. Sometimes, competing business engage in ad wars as a way of undermining or whittling down the influence of competitors so as to gain an upper hand or leverage. Whereas the end users or consumers might be ignorant to the whims and manoeuvring of these businesses, they tend to admire the seeming ingenuity of some of these commercials. In recent times, the advertising space witnessed a series of ad wars which culminated in the "I don Port" commercial by MTN Nigeria. This research aims to evaluate the response of end users to this commercial vis-àvis celebrity endorsement which is embodied in the commercial. The survey methodology was adopted whereas GSM subscribers in Ajuwon/Alagbole in Ifo Local Government Area of Ogun State in Nigeria was the target audience. Results showed that such celebrity endorsements do little to improve the fortunes of businesses. The research findings also recommend that further studies should be done to ascertain if consumers who migrated ("ported") to MTN from other networks, ported back to their original networks.
\end{abstract}

Keywords: network operator, mobile number portability, celebrity endorsement, brand

\section{INTRODUCTION}

It is an indubitable fact that the success of every product is traceable to the objective use of an advertising campaign. While it may sometimes be the case that the turnover of a product can be achieved through manipulation of information, knowing full well that consumers may be influenced and swayed by the hypes about the product. It therefore follows that to fully realize the potentials and usefulness which advertising may bring, it must be one that is truthful, objective, and totally captures the product vis $-\mathrm{a}-\mathrm{vis}$ the consumers to whom the message is targeted. The process of advertising involves the use of structured non-personal communication of persuasive messages on a product or service. Advertising can be likened to "a channel or conduit pipe through which the usefulness of the product is known to the consumers with a view to persuading the consumers to purchase the product" Furthermore, "advertising is a very powerful source in the society, and it can be used to build or destroy. Nothing can be more destructive than the indiscriminate and uncontrolled use of messages" (Arens, 2004 p.7).

Advertising messages are designed using campaign strategies that best appeals to the target consumers, with an intent to persuade them enough to foster patronage. Messages are disseminated to target consumers via the mass media such as television, radio, newspaper, billboard and the Internet. The use of celebrity endorsements are sometimes employed by brand names and products aspiring for brand status.

While income clearly matters in this regard, it would be a mistake to believe that the poor have no visual concerns, or that the rich are always ignorant to the need for basic essentials. The central point is that a variety of needs can be fulfilled through consumption, and it is reasonable to suggest that consumer's needs are often sufficiently recognized and motivating to many consumers. Products and services should provide benefits that fulfil consumer's needs; hence, one of the advertisers' primary job is to create connection between the two for the consumers (Chibueze, 2010). 
The evoked set is usually highly related to the consideration set, the set of brands the consumer would consider to purchase. The consideration set is the subset of brands from a particular product category that becomes the focal point of the consumer's evaluation. It is critical for advertisers to have as complete an understanding as possible of the evaluative criteria that consumers use to make their buying decisions. They must know how consumers rate their brand in comparison with others (O’Guinn, Allen \& Semenik, 2009 pp.155 - 157).

This simply means the consumer will be able to judge the difference between services provided by MTN and other service providers. Hence, given the ability to judge, consumers would be able to determine the best network service provider. Therefore, the price in which the potential consumers will purchase a product must not be too exorbitant when compared to the usefulness or purpose of the product otherwise referred to as value proposition. For example, while the popular MTN advert titled "I Don Port" largely receives consumers' thumbs up because of the danceable lyrics, innovativeness and the comical relief it provides, it remains to be seen whether the advert has indeed translated in the migration ("porting") of network subscribers from other network service providers to MTN.

In the year 2001, MTN was licensed by the NCC (Nigerian Communication Commission) to operate in Nigeria (Adediran, Usman \& Onyedibe, 2005). Since then, industry watchers have observed with keen interest the growth of their popularity especially as it pertains to their unique advertisement with notable jingles. In 2013, MTN keyed into the NCCs initiative; Mobile Number Portability (MNP), aimed at allowing subscribers the capability to migrate from one network service provider to another while retaining their phone numbers. What this means is that a subscriber who is uncomfortable with the quality of service offered by a network service operator was free to migrate to another operator without having to acquire a new SIM (Subscriber Identity Module) from another network service operator. This was lauded as a welcome development aimed as asserting the claim that "the customer is indeed king" (NCC, 2013).

In view of the foregoing, MTN launched the "I Don Port" campaign with a commercial, which industry commentators deemed scathing to their competitors especially Etisalat (See video on Youtube - (https://www.youtube.com/watch?v=y1xbGGQyJwQ or https://youtu.be/y1xbGGQyJwQ). This was especially in view of the fact that the principal cast "Saka", a popular comedian was hitherto associated with the Etisalat brand. The fallout of this event necessitated this research. The question then is did the viewers actually understand the "porting" process presented in the advert? Secondly, did it actually cause subscribers of others networks to port to MTN? Hence, this study seeks to understand the influence of the campaign on subscribers porting decision.

\section{RESEARCH QUESTIONS}

1. What is the level of understanding of the porting process by GSM subscribers in Ajuwon/ Alagbole, Ifo Local Government Area (LGA), Ogun state, Nigeria?

2. How do GSM subscribers in Ajuwon/ Alagbole IFO LGA, Ogun State perceive the MTN "I don port campaign"?

3. What is the rate of porting by other subscribers to MTN?

4. What is the effect of celebrity endorsement on their decision to port to MTN?

5. How do subscribers perceive the quality of MTN services following the porting campaign?

\section{THEORETICAL FraMEWORK}

The study is premised on the Information Processing Theory. This theory was propounded in 1963 by Williams J. McGuire. The theory suggests that attitude change involves steps, with each step being a necessary precedent for the next. The steps are as follows:

1. The persuasive message must be communicated

2. The receiver will attend to the message

3. The receiver yields to and is convinced by the arguments presented

4. The newly adopted position is retained

5. The desired behaviour takes place 
Furthermore, the Information processing model offers fresh insight into the routine handling of information and also challenges some basic assumption about the way sensory data is perceived and applied. The information processing model, humans are unable to be conscious of more than a very small fraction of the information present in an environment. As large quantities of information gets absorbed, only a small fraction of it is consciously retained. One advantage of the information processing theory is that it provides a more objective perspective to learning. (Baran \& Davis, 2012)

The theorem further holds that any independent variable in the communication situation can have an effect on any one or more of the steps. A variable such as intelligence might lead to a less yielding, attitudinal change because the more intelligent person is better able to detect flaws in an argument, and is more willing to maintain an opinion not held by others. But it might lead to more attention because the more intelligent person has a greater interest in the outside world. The theorem goes further to point that it is typical for independent variables to affect one step in a positive way and another in a negative way. A fear appeal, for instance might increase attention to the message (step 1), but interfere with yielding to the arguments presented (step 4).

McGuire (1976), presented eight steps in the information processing theory: (i) exposure, (ii) perception (iii) comprehension (iv) agreement (v) retention (vi) retrieval (vii) decision-making and (viii) action.

In the opinion of Seveirin and Tankard (1992), few previous theories have addressed all of the components of attitude-change, and a few, if any, attitude-change studies looked at the effects of independent variables on all these steps. In fact, as McGuire (1976), pointed out, most of the extensive attitude-change literatures probably focused on the step of yielding or agreement. Therefore, it can be seen that this theory is relevant for this study as it enlightens the researcher about the way consumer processes information accordingly from one step/process to another (Miller, 2001).

\section{LITERATURE REVIEW}

Advertising is a paid form of communication although, some forms of advertising such as public service, use donated space and time. Not only is this message paid for, but the sponsor is identified. In some cases, the point of the message is simply to make consumers aware of the product or company, although, most advertising tries to persuade or influence the consumer to do something. The message is conveyed through many different kinds of mass media reaching a large audience of potential consumers. Because advertising is a form of communication, it is also non-personal. A definition of advertising would include all six of those elements (Wells, Burrett \& Moriarty, 1998, p.13).

In view of the foregoing, the Advertising Practitioners Council of Nigeria (APCON) defines advertising as a communication in the media paid for by identifiable sponsor(s) and directed at the targeted audience with the aim of imparting information about a product, service, idea, or opinion (Oluga, 2010). It can also be defined as any paid form of non-personal communication about an organization, product, service, or idea by an identified sponsor. The paid aspect of this definition refers to the space and time for an advertising message which generally, must be bought. An occasional variation to this is the public service announcement (PSA), who's advertising space or time is donated by the media. (Belch \& Belch 2001 p.15)

From all these definitions, it can be seen that advertising is incomplete without communication, identified sponsor, audience, media, message, awareness, perception. The main aim of an advert can therefore be seen as one that would reach its target audience and satisfy the identified sponsor.

\section{Mtn "I Don PorT" Television Campaign}

The total number of subscribers to telephone lines as at the end of December 1986 was put at around 230,000 while Telex subscribers were only 5,300 in number. Total installed capacity for telephone then was 320,834 and telex 11,577. The percentage utilisation for telephone therefore was 71.6 per cent while telex was approximately 45.7 per cent. However, modernity in telecommunications provided facilities that allowed for new class of service, improved revenue generation with properly reviewed tariff policy. As at 1996, the country had about 1,000,000 subscribers to telephone lines all of which were handled by standard A antennae facing both the Indian and the Atlantic Ocean Regions installed at four (4 NO.) different geographical locations across the country. Nigeria operated a Domestic Satellite System by leasing three (3 No.) transponders from INTELSAT which were accessed by nineteen (19 No.) Standard B earth stations in some state capitals of the Federation. 
There was a Territorial Manager responsible for Telecommunications Administration in each state except Lagos state due to the relatively large number of switching centres and subscribers in the metropolis, it was considered prudent to have at least two (2No.) Territorial managers (Alabi, 1996).

The Nigerian Communications Commission (NCC) announced the number portability option for customers which allows subscribers to migrate from one mobile network provider to another without requiring the acquisition of a new SIM or phone number. This long overdue feature triggered ad wars amongst the telecom providers in Nigeria. Before now, statistics had showed that MTN had the largest number of subscribers in Nigeria hence, the belief that MTN would be the worst hit as many MTN subscribers have continued to complain about their unsatisfactory quality of service (Oniyitan 2013).

It is as a result of this that the MTN advert took industry watchers by storm and went viral with widespread attestation to the creativity and intrigue. One would expect that with such an amazing ad would follow expected results. However, it would seem that this was not the case. According to a recent survey, statistics as at 25th April 2013 11am show that Etisalat continues to firmly lead the charts. Airtel surprisingly in a very solid second position, GLO in the third position and MTN last (Oniyitan 2013).

Whether the television, newspapers, posters, radio, billboards, social media and other media platforms, advertising has become the watershed instrument for engaging consumers. It is therefore no doubt that some advertorial content are aimed at distorting the mind of the less suspecting and nondiscerning consumer, who view this offerings as a mere awareness tool to promote a brand or product.

A notable brand strategist, gave a panoramic view about the ironical twist of NCC assessment card, which has whittled down the impact of MTN's marvellous advert. "With the huge numbers of MTN users in Nigeria, if five per cent of its subscribers port to other networks, the effect will be felt. However, if the same numbers move from Etisalat, it will be so insignificant to other mobile operators. Hence, in as much as the MNP has restored sanity in terms of consumer choice and service delivery, its effect on MTN is immense, as NCC would want us to believe. Also, it has to be said that adverts do not really affect the bottom-line of the brand. The consumer experience of the brand in terms of service delivery and consumer relationship is some of the reasons people refuse to leave their network. It is not necessarily the give-aways and promotions but the emotional appeal and top of mind awareness, which makes the brand evergreen in the mind of consumers. Consumers know that there is no perfect network so they still choose to stick with their preferred choice because the client service and other public relations channels constantly address challenges," he said (Madike 2013).

The opinion of Lead strategist/CEO, Absolute PR, Mr.Ekine Akonte is not radically different. His words: "In fairness to the release from NCC, I strongly believe that it all has to do with perception deficiency on the part of the consumers. It is believed that Etisalat is quite young, ambitious and have a better service delivery, while MTN is old and cannot boast the same quality delivery as Etisalat. In spite of the razzmatazz which the Saka advert generated, it should also be said that advert is just one of the marketing communication tools that is deployed for any brand campaign. There are testimonial, word of mouths and a gamut of media that can sustain brand engagement. Hence, MTN should stop behaving like a dinosaur and start reinventing itself like the phoenix."

It is being said and emphasised around several business climes from time immemorial that 'the consumer is king'. Even this fact has been engrafted in the economic by-law that no product, irrespective of its unique value proposition, is incomplete until it arrives at the 'kingly doorstep' of the consumer. Clearly, this profound and axiomatic assertion could be alluded as a compelling reason that business strategists, brand owners and corporate organisations periodically splash out seemingly incredible and unbelievable monetary benefits in a calculated move to endear consumers to its products and shore up.

\section{Methodology}

The survey method was adopted using questionnaires as instruments to sample a cross section of the target audience. A sample size of 250 people between the ages of 14 to 60 of Ajuwon Alagbole Ogun State, Nigeria were conveniently selected since they are the target population under study. In order to facilitate easy analysis and interpretation of data, a smaller sample size was selected for effective management. 


\section{Presentation and Discussion of Findings}

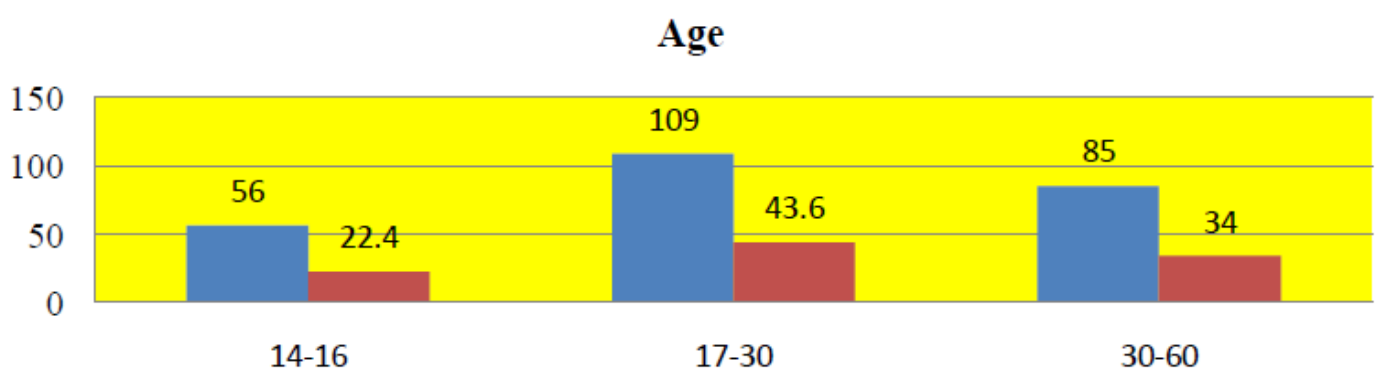

Fig1. Distribution of respondents by Age

Out of the 250 questionnaire distributed in the study, it was observed that 56(22.4\%) of the respondent were in the age group 14-16years, 109(43.6\%) are between $17-30$ years, 85(34.0\%) are between $30-60$ years. With this result, the respondents between ages 14-16 responded more to this study than other age groups (See figure 1).

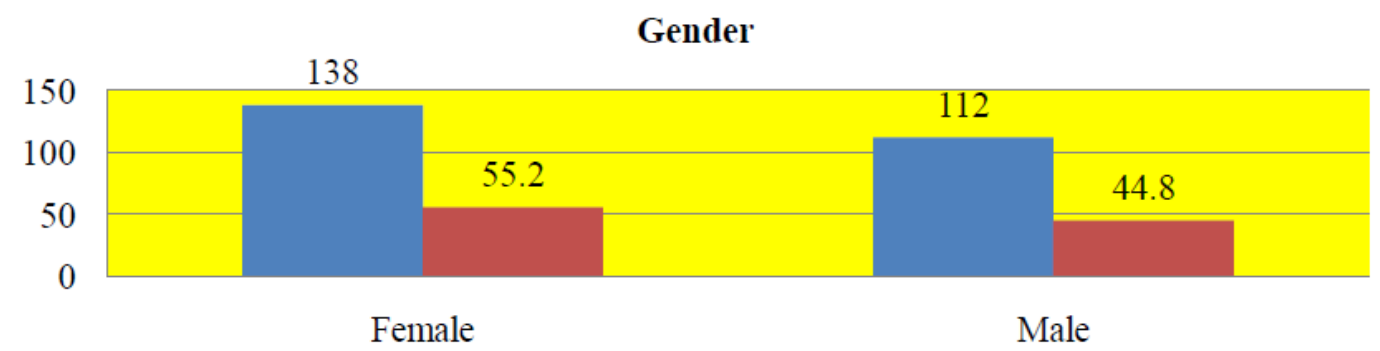

Fig2. Distribution of respondent's gender

As shown in figure 2, the sex distribution of the respondent showed 138(55.2\%) are Female, while $112(44.8 \%)$ are Male. With this result, females responded more to this study.

Network subscribtion

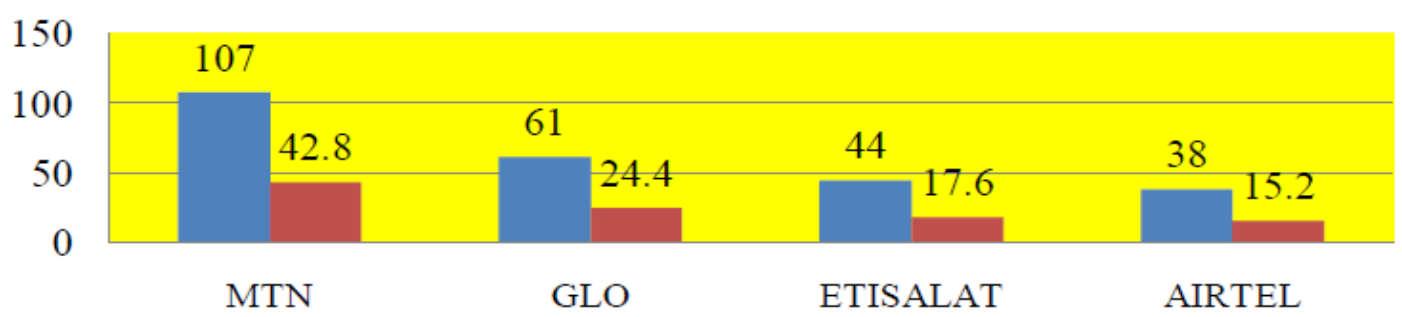

Figure3. Distribution of respondents by network subscription

The study also revealed that 107 (42.8\%) subscribed to MTN network, 61(24.4\%) subscribed to GLO network, 44(17.6\%) subscribed to ETISALAT network, while 38(15.2\%) subscribed to AIRTEL network. With this information, MTN has more subscribers in this area of research (See figure 3).

Research Question 1: What is the level of understanding of the porting process by GSM subscribers in Ajuwon/ Alagbole IFO LGA, Ogun state?

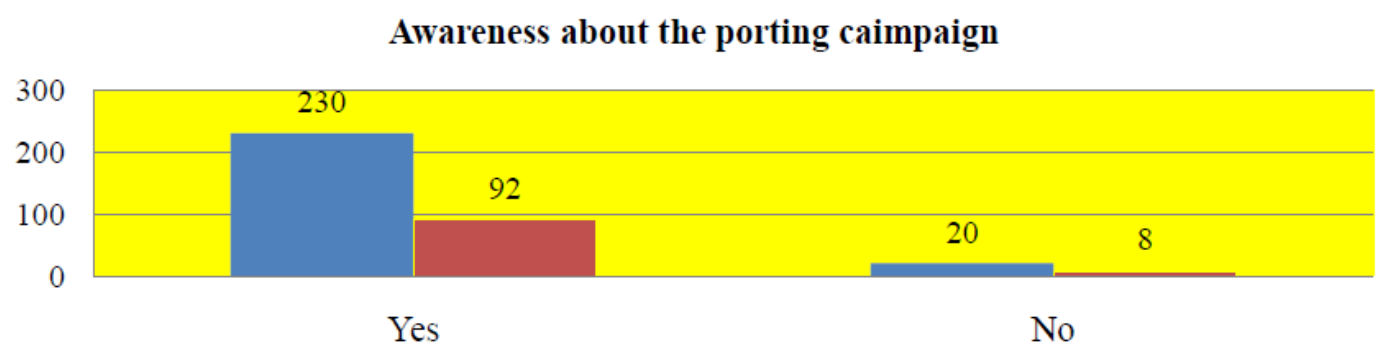

Fig4. Distribution of respondent's awareness about the porting campaign

From the study as seen in figure 4, it was discovered that 230(92.0\%) have heard about the porting campaign, 20(8.0\%) have not heard about the porting campaign. Therefore, a large percentage of respondents are aware of the porting campaign. 
Do you understand the porting process

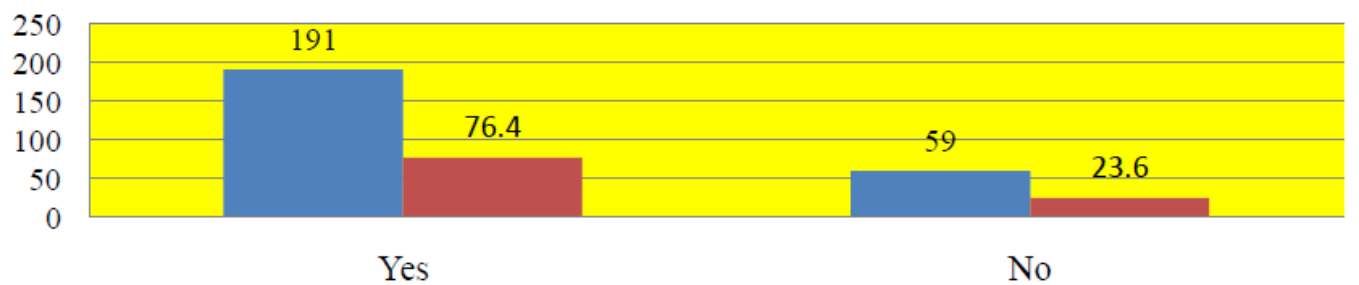

Fig5. Distribution of respondents understanding of the porting process

Out of the 250 questionnaires distributed, 191(76.4\%) understand the porting process, while $59(23.6 \%)$ do not understand the porting process (See figure 5).

\section{Research Question 2: How do GSM subscribers in Ajuwon/Alagbole IFO LGA, Ogun state perceive the MTN "I don port campaign?}

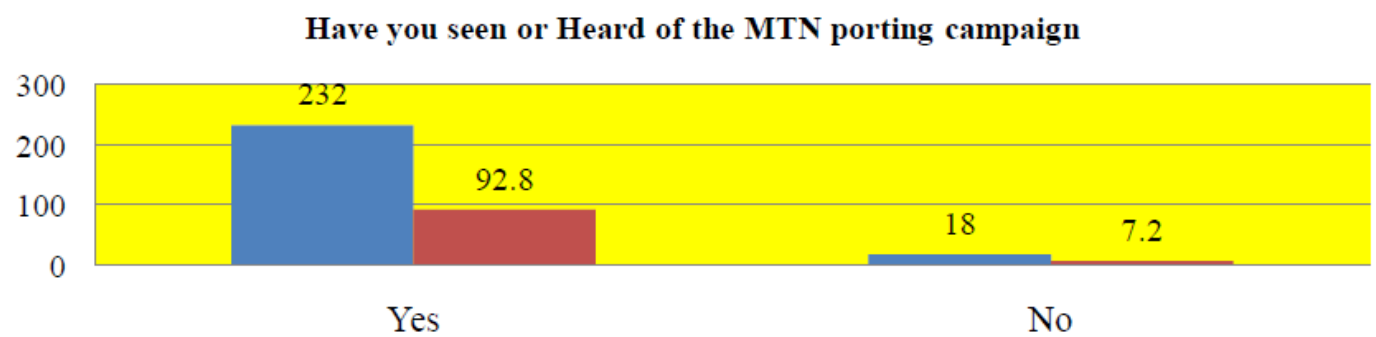

Fig6. Distribution of respondents showing the awareness of the MTN porting campaign

The information in figure 6 reveals that $232(92.8 \%)$ of the respondents have both seen and heard of the MTN porting campaign. The study further revealed that Eighteen (7.2\%) of respondents had not both seen and heard of the MTN porting campaign. This means that an above average of the respondents have seen or heard about the MTN porting campaign. From this study it is shown that the awareness pattern used by MTN is good.

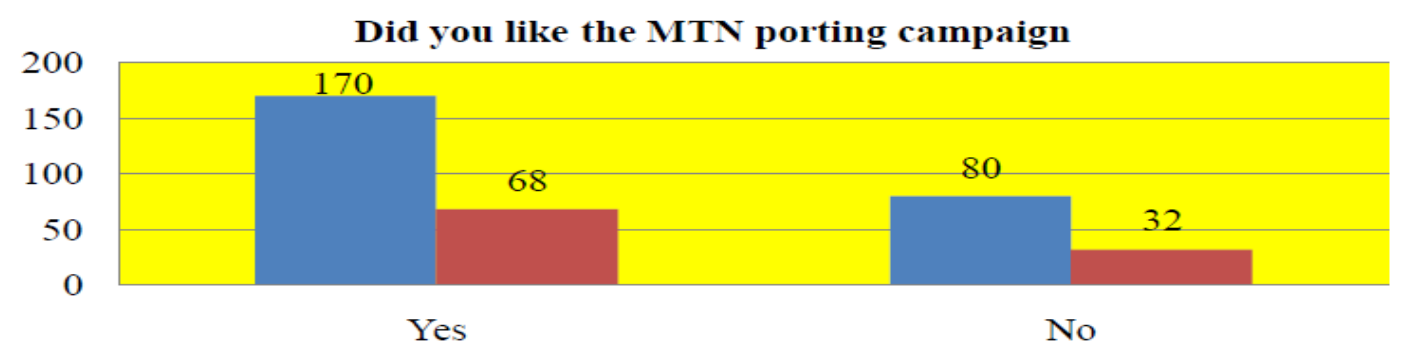

Fig7. Distribution of respondent's attitude towards MTN porting campaign

Figure 7 reveals in this study that $170(68.0 \%)$ of the respondents like the MTN porting campaigns, $80(32.0 \%)$ did not like it. In the former table that reveals that respondents believe that MTN's porting campaign is the most attractive campaign compared to other network so is it also present in this table that an above percentage of respondents like the MTN porting campaign

\section{MTN porting advert is the most attractive}

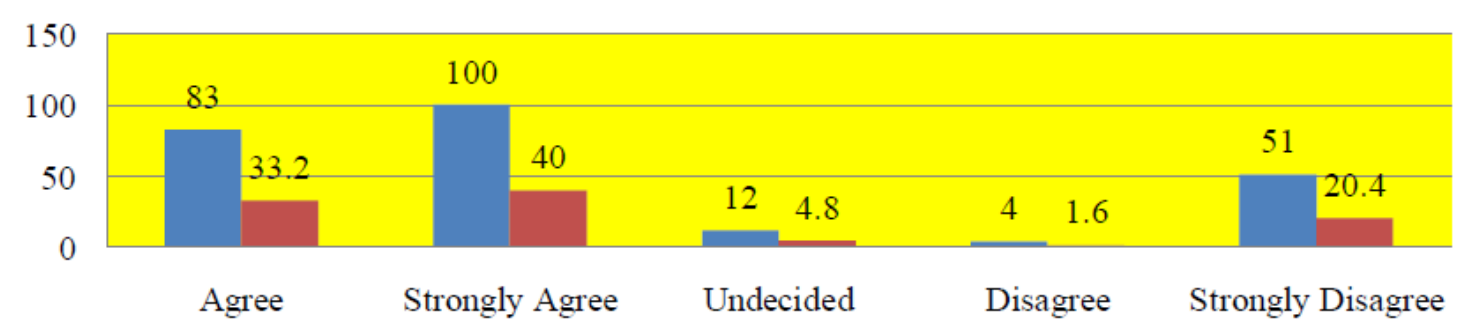

Fig8. Distribution showing response that MTN porting advert is the most attractive

The information in figure 8 reveals that $83(33.2 \%)$ agree and 100(40.0\%)) strongly agreed that MTN is advert is the most attractive. The participants who were undecided in the study were $12(4.8 \%)$. However 4(1.6\%) Disagree and 51(20.4\%) Strongly Disagreed that MTN advert is the most attractive. With this information, it can be seen that respondents see MTN advert as the most attractive. 
Research Question 3: What is the rate of porting by other subscribers to MTN?

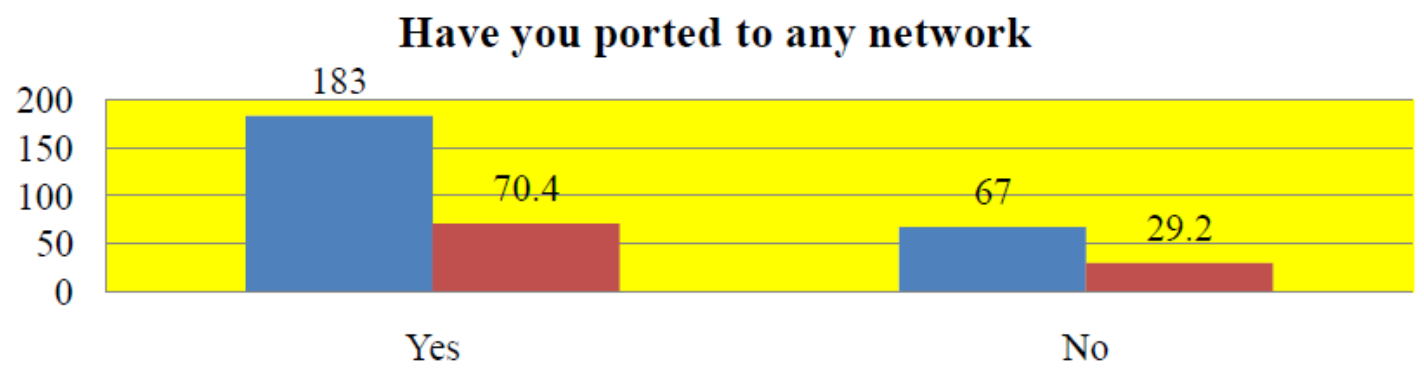

Fig9. Distribution of respondents that have ported

The study reveals in figure 9, that 183(70.8\%) have ported, while 67(29.6\%) have not ported. Due to the awareness of the porting campaign, the respondents of this study that have ported is above average

If yes, to what network

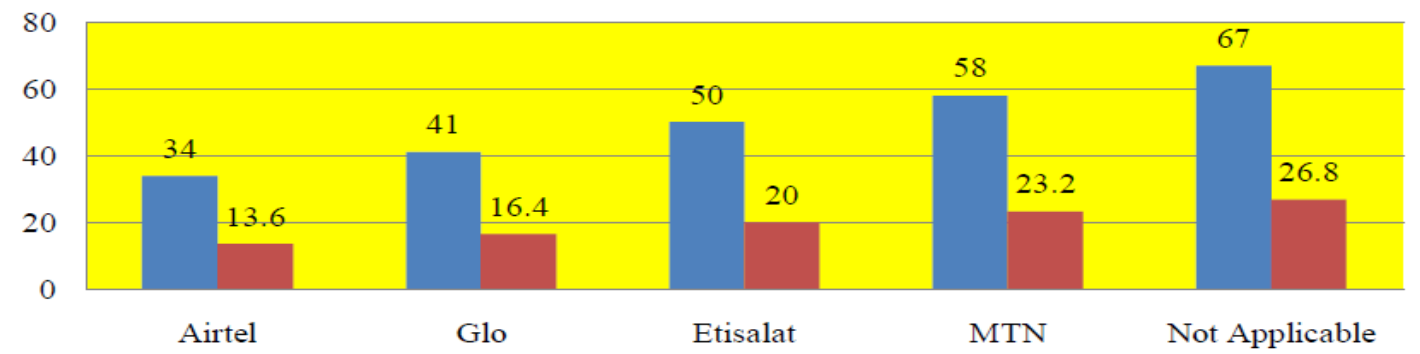

Fig10. Distribution of respondents that have ported to a particular network

The analysis of the distribution of porting reveals in figure 10 that 34(13.6\%) respondents have ported to AIRTEL, 41(16.4\%) to GLO, 50(20\%) to Etisalat, 58(29.6\%) to MTN and 67(26.8\%) have not ported. The respondents of this study that ported to MTN is below average.

Research Question 4: What is the effect of celebrity endorsement on their decision to port to MTN?

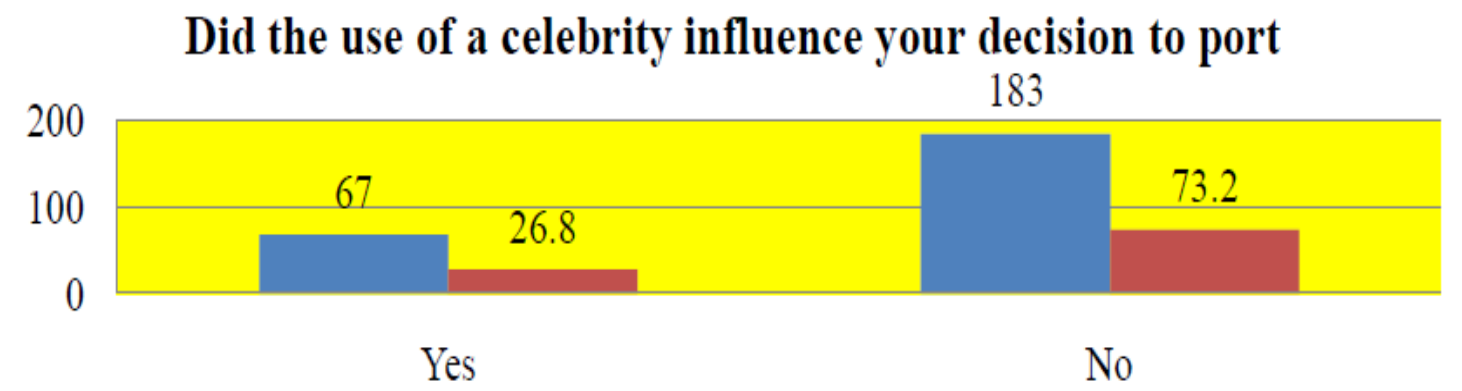

Fig11. Distribution of respondents that were influenced to port due to the use of a celebrity

When the effect of celebrity endorsement on decision to port was analysed as shown in figure 11, it was discovered that out of the 250 questionnaire distributed in the study, it was observed that $67(26.8 \%)$ of the respondent said that the use of celebrities influenced their decision to port, whereas 183(73.2\%) said that celebrities had no effect on their decision. A higher percentage of respondents agreed that the celebrity endorsement had nothing to do with their porting behaviour.

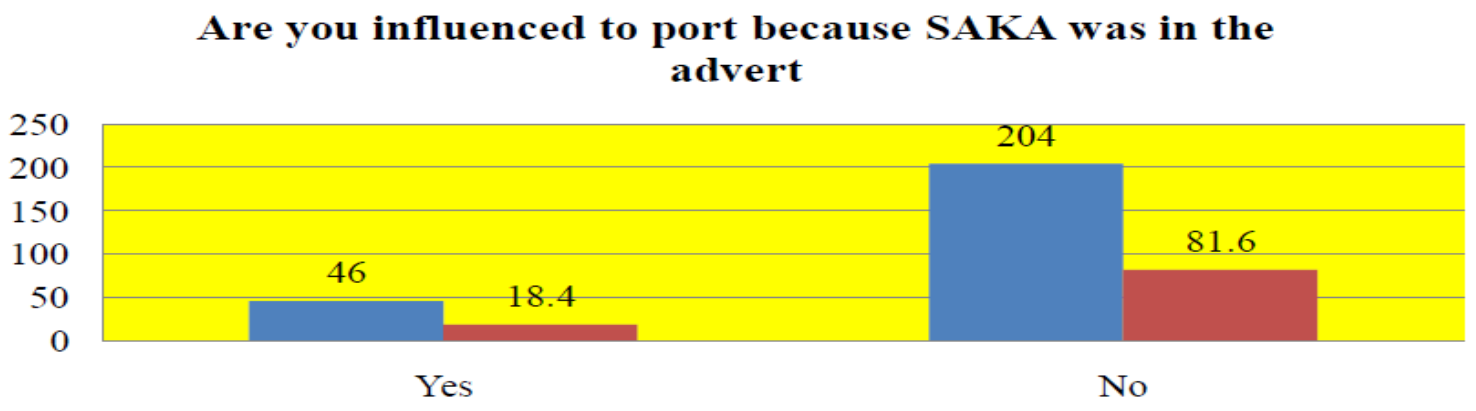

Fig12. Distribution of respondents who ported because SAKA was in the advert 
The study revealed that 46(18.4\%) were influence by Saka to port while 204(81.6) were not influenced by him. From this, it can be seen that even though MTN made use of a celebrity in their adverts, that didn't influence the respondents of this study to port (See figure 12).

\section{Research Question 5: How do MTN users perceive the quality of their services following the porting campaign?}

\section{The quality ofMTN's service has improved following the porting campaign}

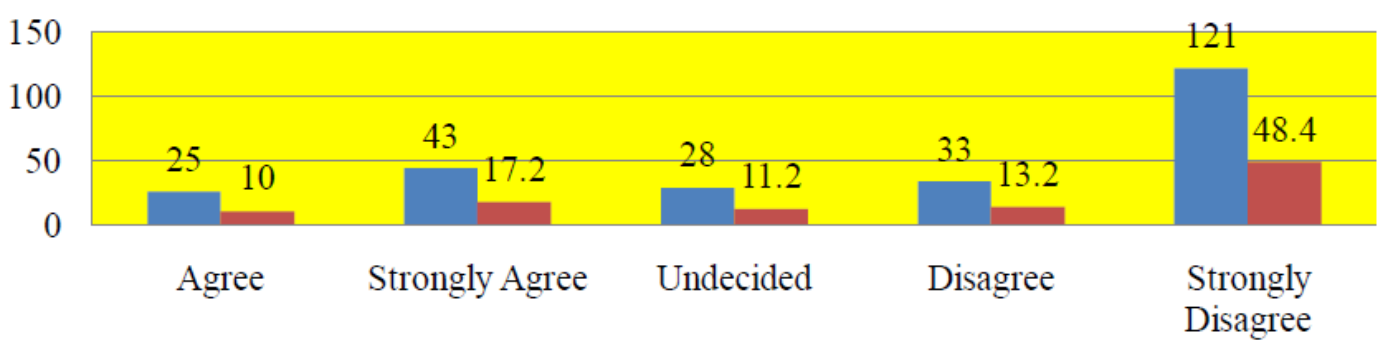

Fig13. Distribution of respondent's view of the quality of their services following the porting campaign

Figure 13 shows that out of the 250 participants engaged in the study, 25 (10.0\%) strongly agreed that the quality of MTN has improved following the porting campaign. This is closely followed by 43(17.2\%) that agreed, $28(11.2 \%)$ were undecided. Thirty three 33(13.2\%) disagreed, whereas 121 $(48.4 \%)$ strongly disagreed to the statement that the quality of MTN has improved following the porting campaign. With the following information, it can be seen that MTN's network did not show much progress in this area of study as an above percentage of respondents strongly disagree that MTN has improved following their porting campaign.

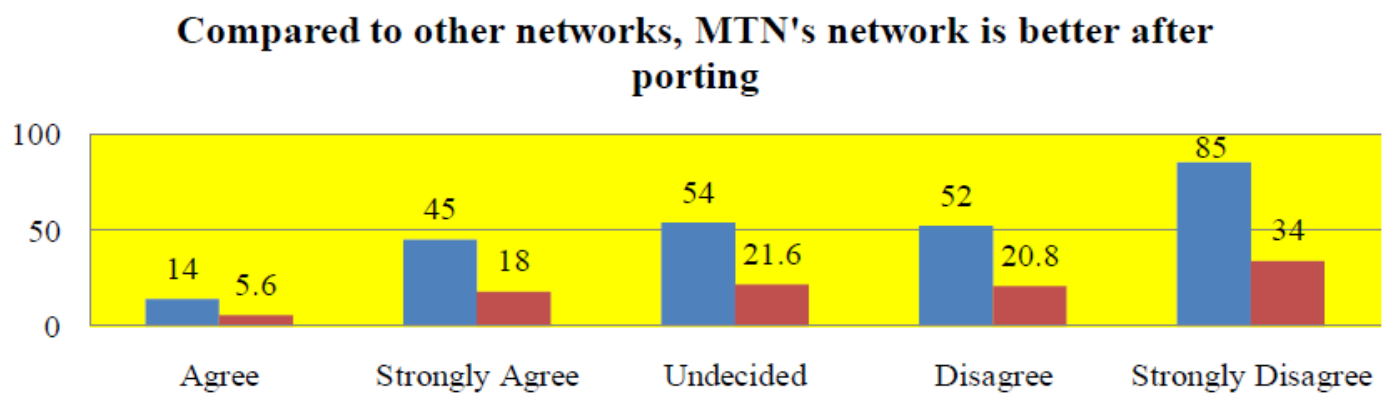

Fig14. Distribution showing responses that MTN's network is better after porting

From the information shown in figure 14, 14(5.6) respondents agreed that MTN's network is better after porting, 45(18.0) strongly agree, 54(21.6) undecided, 52(20.8) agree, 85(34.0) strongly disagree. With this, majority of the respondents strongly disagree that MTN's network is better after porting.

MTN renders better quality of service than other Network

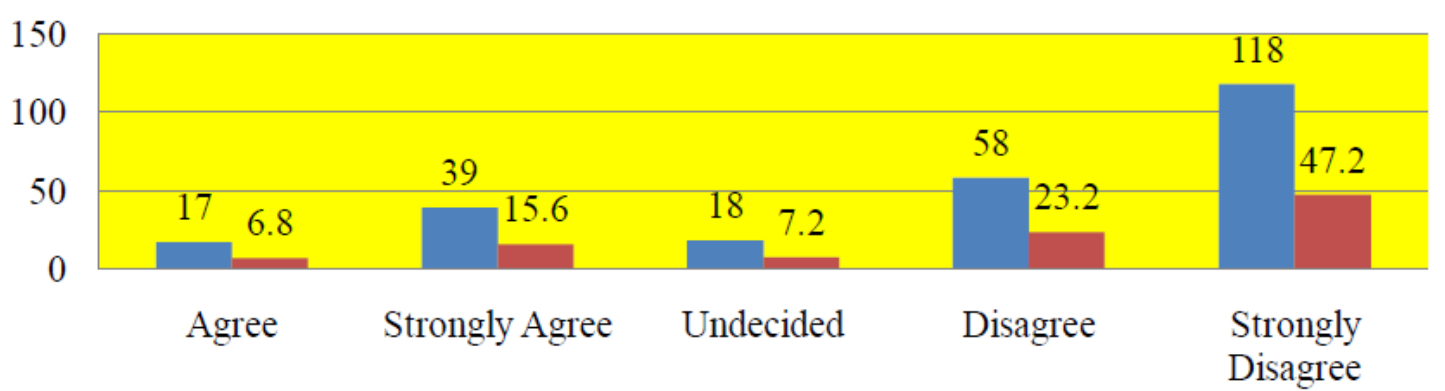

Fig15. Distribution showing responses that MTN renders better quality service than other network

Figure 15 shows that $17(6.8 \%)$ agreed, 39(15.6\%) strongly agreed that MTN renders very good quality of service than other operator networks. The proportion of participants that disagreed and strongly disagreed that MTN render better quality services than other operator networks were 58 $(23.2 \%)$ and $118(47.2 \%)$ respectively. Those who are indifferent were $18(7.2 \%)$. Out of 250 respondents, 118 strongly disagree that MTN renders very good and acceptable quality of service than any other network. 


\section{MAJOR FindingS}

1. Figure 4 showed that $230(92 \%)$ of respondents are aware about the porting campaign. This means the advertising strategy employed by MTN was a successful one.

2. Figure 5 revealed that $191(76.4 \%)$ respondents understand the porting process

3. Figure 7 showed that 232(92.8) respondents are aware of the MTN porting campaign

4. Figure 7 also indicated that $170(68 \%)$ respondents like the MTN porting campaign

5. Figure 8 showed that $100(40 \%)$ respondents strongly agree that MTN porting advert is the most attractive.

6. Figure 9, showed that 183(70.4\%) respondents have ported.

7. Figure 10, indicated that $67(26.8)$ respondents were not applicable in porting to a particular network

8. Figure 11 showed that $183(73.2)$ respondents were not influenced to port due to the use of a celebrity.

9. Figure 12 indicated that 204(81.6\%) respondents were not influenced to port because Saka was in the advert

10. Figure 13 revealed that 121(48.4) of respondents strongly disagree that the quality of MTN service has improved following the porting campaign

11. Figure 14 showed that $85(34 \%)$ of respondents strongly disagree that compared to other networks MTN's network is better after porting

12. Figure 15, showed that $118(47.2 \%)$ respondents strongly disagree that MTN renders quality service compared to other networks.

\section{CONCLUSION AND RECOMMENDATIONS}

From the data gathered through the use of questionnaires, findings indicate that MTN porting campaign is very attractive compared to other porting adverts but network still remains relatively poor. Further findings also reveal that, the use of celebrity endorsement didn't guarantee that the respondents would port to MTN from other network operators, however, it created awareness. This research work consequently validated the influence of MTN "I DON PORT" advert on subscribers porting behaviour. In the light of the analysis and interpretation of data collected in the research field, this research work recommends the following:

1. MTN network needs to improve in their service especially in the area where this research was done as the findings of this research reviewed that subscriber's view MTN service to be poor compared to other network providers.

2. MTN needs to educate their subscribers more on the porting process because when adverts or promos such as "I don port" are made, not all the subscribers are knowledgeable enough to understand the cause and effects of the promotion.

3. Proper research should be done in cross-checking the role of the celebrity in influencing the consumer to consume or patronize the product or service. Note should be taken that popular and established brands like MTN may not need a celebrity endorsement for its service or product to be purchased.

4. Subscribers should always lodge their various complains through the use of the customer care call centres.

5. Further study should be done to ascertain if people that ported to other networks ported back to their original networks.

\section{REFERENCES}

[1] Adediran Y.A, Usman A.U. \& Onyedibe B.N. (2005). Nigeria's Telecommunication Industry in the New Millenium: Problems, Challenges and Prospects. The 6th Annual Engineering Conference Proceedings, FUT, Minna June 2005. Retrieved from 
Chioma, Patricia E. (Phd) et al.

https://www.unilorin.edu.ng/publications/adediranya/Nigeria's\%20Telecommunications\%20Indu stry\%20in\%20the $\% 20$ Neew $\% 20$ Millenium\%20Problems\%20Challanges\%20and\%20Porspect.p df

[2] Alabi G.A (1996). Telecommunications in Nigeria. University of Pennsylvania - African Studies Centre. http://www.africa.upenn.edu/ECA/aisi_inftl.html Arens, F.W (2004) Contemporary Advertising 9th edition, New York: The McGraw-Hill Companies.

[3] Baran S.J. and Davis D.K. (2003). Mass Communication Theory. Foundations, Ferment and Future. Sixth Edition. Copyright 2010 Cengage Learning.

[4] Belch, E. and Belch, A. (2001) Advertising and Promotion $4^{\text {th }}$ edition.united states: Gary Burke.

[5] Chibueze, J. (2010) History of Advertising retrieved 12/11/13 from http://freelartdesigns.wordpress.com/nigeria50-thestory-of-advertsing/-

[6] Madeke I. (2013). Mobile Number Portability: The benefits, the obstacles. National Mirror April 28, 2013. http://nationalmirroronline.net/new/mobile-number-portability-the-benefits-theobstacles/.

[7] McGuire, W.J. (1976). Some internal psychological factors influencing consumer choice. Journal of Consumer Research, 2 (4), 302-319.

[8] Miller, K. (2001) Communication Theories -Perspectives Process and ContextsNew York: The McGraw-Hill Companies.

[9] Nigerian Communications Commission (2013) Factors which Influence Customer Buying Decision retrieved 18/11/13 from http://w-hbs.com/factors-which-influence-customer-buyingdecision-the-nigerian-industry-advertising-war-on-number-portability/

[10] O'Guinn T, Allen C and Semenik R. (2009). Advertising and Integrated Brand Promotion $5^{\text {th }}$ edition. United States: Cengage Learning.

[11] Oluga S.O. (2010). A Critique of Linguistic and Non-Linguistic Innovative Techniques of Contemporary Nigerian Advertisements. Pakistan Journal of Social Sciences. Year: 2010 | Volume: 7 | Issue: 4 | Page No.: 318-324. DOI: 10.3923/pjssci.2010.318.324

http://www.medwelljournals.com/fulltext/?doi=pjssci.2010.318.324.

[12] Oniyitan O. (2013). Factors Which Influence Customer Buying Decision - The Nigerian Telecoms Industry Advertising War on Number Portability. Copyright (C) 2015 W-Holistic Business Solutions. All Rights Reserved. http://w-hbs.com/factors-which-influence-customerbuying-decision-the-nigerian-telecoms-industry-advertising-war-on-number-portability/

[13] Severin, W.J. and Tankard W.J. (1992). Communication Theories: Origins, Methods, and Uses in the Mass Media, 3d ed. White Plains, NY: Longman Publishing Group.

[14] Wells Burrett, Moriaty(1998)Advertising Principles and practice 4th edition. New Jersey: A Simon and Schuster Company. 